\title{
Editorial
}

\section{Earth Observations and Societal Impacts}

\author{
Yuei-An Liou, ${ }^{1,2}$ Chung-Ru Ho, ${ }^{2,3}$ Yuriy Kuleshov, ${ }^{4}$ and Jean-Pierre Barriot ${ }^{5}$ \\ ${ }^{1}$ Center for Space and Remote Sensing Research (CSRSR), National Central University, Chungli 32001, Taiwan \\ ${ }^{2}$ Taiwan Group on Earth Observations, Zhubei 30274, Taiwan \\ ${ }^{3}$ Department of Marine Environmental Informatics, National Taiwan Ocean University, Keelung 20224, Taiwan \\ ${ }^{4}$ Bureau of Meteorology, GPO Box 1289, Melbourne, VIC 3001, Australia \\ ${ }^{5}$ Geodesy Observatory of Tahiti, University of French Polynesia, BP 6570, 98702 Faaa-Tahiti, French Polynesia
}

Correspondence should be addressed to Yuei-An Liou; yueian@csrsr.ncu.edu.tw

Received 4 May 2014; Accepted 4 May 2014; Published 5 June 2014

Copyright (C) 2014 Yuei-An Liou et al. This is an open access article distributed under the Creative Commons Attribution License, which permits unrestricted use, distribution, and reproduction in any medium, provided the original work is properly cited.

\begin{abstract}
"You cannot manage what you cannot measure." It is an old adage that is still true today. Unless we observe and measure the Earth environment in a consistent manner, we cannot effectively manage it for improvement. "Earth Observation" thus plays an increasing important role in the sustainable development of the globe. It involves the very close investigation and measurement on the Earth and the derived results from the direct or indirect observations and measurements are the crucial information used to construct the supporting policies for the environments, postdisaster management, and so forth [1-6].
\end{abstract}

The 3rd International Conference on Earth Observations and Societal Impacts, ICEO\&SI 2013 (http://2013.iceo-si.org.tw/home), followed the tradition set by the previous meetings (ICEO\&SI 2011 and 2012) by focusing on observations of the Earth environment and their societal impacts. With the success of ICEO\&SI 2013 jointly cohosted by Taiwan Group on Earth Observations (http://tgeo.org.tw/) and National Cheng Kung University, more than 250 academics, researchers, engineers, and students from 15 countries had wonderful stays in Tainan. All in all, 104 papers were presented in 12 sessions including 5 keynote speeches, 56 oral papers, and 43 posters, which turned into this special issue as one of the academic fruits. This special issue consists of 10 articles, which are ordered according to topic: weather/climate, disasters/energy, and water/agriculture. The main scientific findings are briefly introduced below.

Tropical cyclones (called typhoons in the Western Pacific) are the most severe weather phenomena, which have significant impacts on the coastal communities when they approach the coast or make landfall. Preparedness to typhoons is one of the key factors to limit the impact of such devastating events. In this special issue, improving the operational methodology of tropical cyclone seasonal prediction in the Australian and the South Pacific ocean regions has been described. New approach (support vector regression methodology) for estimating tropical cyclone activity in the coming season to assist the Australian Bureau of Meteorology in preparing an operational outlook for the likelihood of an above median number of tropical cyclones seasonally for the Australian region (AR; $5^{\circ} \mathrm{S}$ to $40^{\circ} \mathrm{S}, 90^{\circ} \mathrm{E}$ to $160^{\circ} \mathrm{E}$ ) and the South Pacific Ocean (SPO; $5^{\circ} \mathrm{S}$ to $40^{\circ} \mathrm{S}, 142.5^{\circ} \mathrm{E}$ to $120^{\circ} \mathrm{W}$ ) has been investigated. New explanatory variables to improve the accuracy of seasonal tropical cyclone predictions have also been investigated. Correlation analysis and subsequent cross validation of the generated models show that the Dipole Mode Index (DMI), describing the intensity of the Indian Ocean Dipole, performs well as an explanatory variable for tropical cyclone prediction in both AR and SPO. Other variables, which yielded high correlation with the number of tropical cyclones, were Niño4 SST anomalies (for AR) and Niñol+2 SST anomalies (for SPO region). For both AR and SPO, the developed model which utilised the combination of explanatory variables Niñol+2 SST anomalies, Niño4 SST anomalies, and DMI had the best forecasting performance. The developed model is recommended for operational tropical cyclone seasonal forecasting in the AR and SPO regions.

Aerosols can be found over oceans, deserts, mountains, forests, ice sheets, and so on. They drift in the air from 
the stratosphere to the surface and have major impacts on climate and health. Dust as a kind of aerosols can travel a long distance to affect different areas. The strength of lowlevel trough and surface anticyclonic system are important in determining the transport route of Asian dust event. With model simulations, it is found that the transportation of dusts from Gobi Desert toward Korea is the combination of dusts transported from the desert under westerly wind with particulate matters and gases from vehicles on the road of the city caused high aerosol concentrations near the ground surface maxima during the sunset time.

Through investigating a case study for a typhoon in Taiwan region, unusual warming in the coastal region of northern South China Sea and its impact on the sudden intensification of tropical cyclone Tembin (2012) are described in this issue. Tropical cyclone Tembin (2012) passed twice and made landfall over south tip of Taiwan in August 2012. During its passage, an unusual sea surface warming was observed around $22.5^{\circ} \mathrm{N}, 117^{\circ} \mathrm{E}$ in the coastal region of northern South China Sea. Subsequently, Tembin (2012) passed over this extreme warming region and its intensity was enhanced dramatically from Category 1 to Category 3 within less than 1-day time interval. This unusual warming seems to largely prompt the intensification of Tembin. The results indicate that a distinct positive short-wave radiation influx anomaly may dominate the generation of the unusual warming in the shore region during Tembin's passage. This result is validated by the distributions of free cloudy coverage shown in satellite infrared images.

Advanced Spaceborne Thermal Emission Reflection Radiometer (ASTER) surface temperature data were compared with in situ measurements to validate the use of ASTER data for studying urban heat islands at eight sites in Changwon, Korea, during the summer and fall of 2012. Comparisons showed that ASTER derived temperatures were generally $4.27^{\circ} \mathrm{C}$ lower than temperatures collected by in situ measurements during the daytime, except on cloudy days. However, ASTER temperatures were higher by $2.23-2.69^{\circ} \mathrm{C}$ on two dates during the nighttime. Temperature differences between a city park and a paved area were insignificant. Differences between ASTER derived temperatures and onsite measurements are caused by a variety of factors including the application of emissivity values, while the complex spatial characteristics of urban areas are not considered. Therefore, to improve the accuracy of surface temperatures extracted from infrared satellite imagery, a revised model is proposed whereby temperature data is obtained from ASTER and emissivity values for various land covers are extracted based on in situ measurements.

El Niño-Southern Oscillation is one of the most important climate drivers on the planet and its variability has significant impact on tropical cyclones. In this issue, impacts of two types of El Niño and La Niña events on typhoon activity were presented. The HadISST (Hadley Centre Sea Ice and Sea Surface Temperature) dataset is used to define the years of El Niño, El Niño Modoki, and LaNiña events, from 1950 to 2012, and to find out the impacts of these events on typhoon activity. The results show that the position and the intensity of typhoon are affected by different phases on ENSO. The formation positions of typhoon are farther eastward moving in El Niño years than in La Niña years and much further eastward in El Niño Modoki years. The life time and the distance of movement are longer, and the intensity of typhoons is stronger in El Niño and in El Niño Modoki years than in La Niña years.

Monitoring and warning of geological disasters accurately and in a timely fashion would dramatically mitigate casualties and economic losses. A WebGIS-based information system was designed for monitoring and warning of geological disasters. This system provides scientific suggestions to commanders for quick response to the possibility of geological disaster.

Global change may refer to the changes of atmosphere, oceans, geology, topography, and ecology. It is one of the important issues to the human society. Satellite imagery as a tool is very helpful to detect the changes. Satellite images were used to investigate the evolutions of glaciers and glacial lakes in the Pumqu river basin. They found that the magnitudes of glacier retreat rate and glacial lake increase rate during the period of 2001-2013 are more significant than those for the period of the 1970s-2001. Changes occurred not only by nature, but also by anthropic activities. The impact of changes in farm ponds on the regional agricultural environment in Taoyuan, Taiwan, with multiyear SPOT satellite imagery was explored. Results show that farm ponds have decreased from 1993 to 2010 by human activities. They suggested that, for the sustainable agriculture, farm ponds shall be classified and cherished as a public asset for the future development.

Satellite imagery has been demonstrated usefully for global, regional, and local studies. However, some detailed studies cannot be made with coarse spatial resolution of passive microwave imagery. A geostatistical downscaling scheme was developed to generate fine scale precipitation information from Tropical Rainfall Measuring Mission (TRMM) data. The results of this scheme reflect detailed characteristics with better predictive performance.

This special issue aims to summarize the most recent developments and ideas in the field. It will serve as a valuable asset for the scientists and engineers working on the scientific and technological problems of Earth Observations and various environment issues. Our continuous efforts will illustrate the core mission by inspecting terrestrial environment information to offer solid solutions for the societal needs.

\section{Acknowledgments}

We are grateful to all the authors who contributed to this issue and to all the reviewers whose suggestions have helped improve the quality of the papers published in this issue. 


\section{References}

[1] S. K. Kar, Y. A. Liou, and K. J. Ha, "Aerosol effects on the enhancement of cloud-to-ground lightning over major urban areas of South Korea," Atmospheric Research, vol. 92, no. 1, pp. 80-87, 2009.

[2] Y. A. Liou, S. K. Kar, and L. Y. Chang, "Use of high-resolution formosat-2 satellite images for post-earthquake disaster assessment: a study following the 12 may 2008 Wenchuan earthquake," International Journal of Remote Sensing, vol. 31, no. 13, pp. 33553368, 2010.

[3] Y. A. Liou, H. C. Sha, T. M. Chen et al., "Assessment of disaster losses in rice field and yield after tsunami induced by the 2011 Great East Japan earthquake," Journal of Marine Science and Technology, vol. 20, no. 6, pp. 618-623, 2012.

[4] F. C. Ming, C. Ibrahim, C. Barthe et al., "Observation and a numerical study of gravity waves during tropical cyclone Ivan (2008)," Atmospheric Chemistry and Physics, vol. 14, pp. 641-658, 2014.

[5] C. H. Cheng, F. Nnadi, and Y. A. Liou, "Energy budget on various land use areas using reanalysis data in Florida," Advances in Meteorology, vol. 2014, Article ID 232457, 13 pages, 2014.

[6] Y. A. Liou and S. K. Kar, "Evapotranspiration estimation through remote sensing and various surface energy balance algorithms-a review," Energies, vol. 7, no. 5, pp. 2821-2849, 2014. 

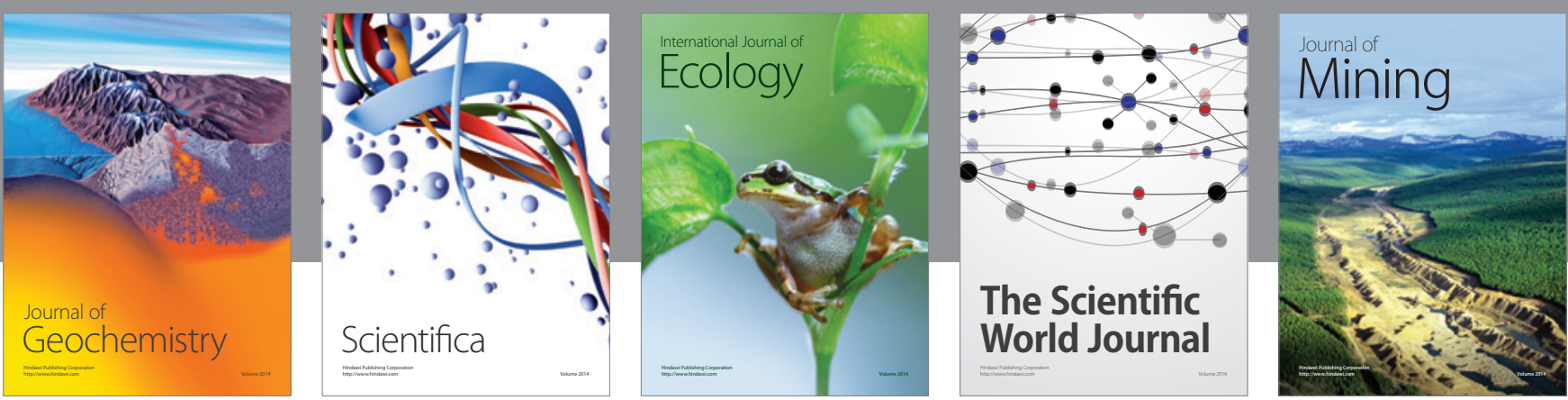

The Scientific World Journal
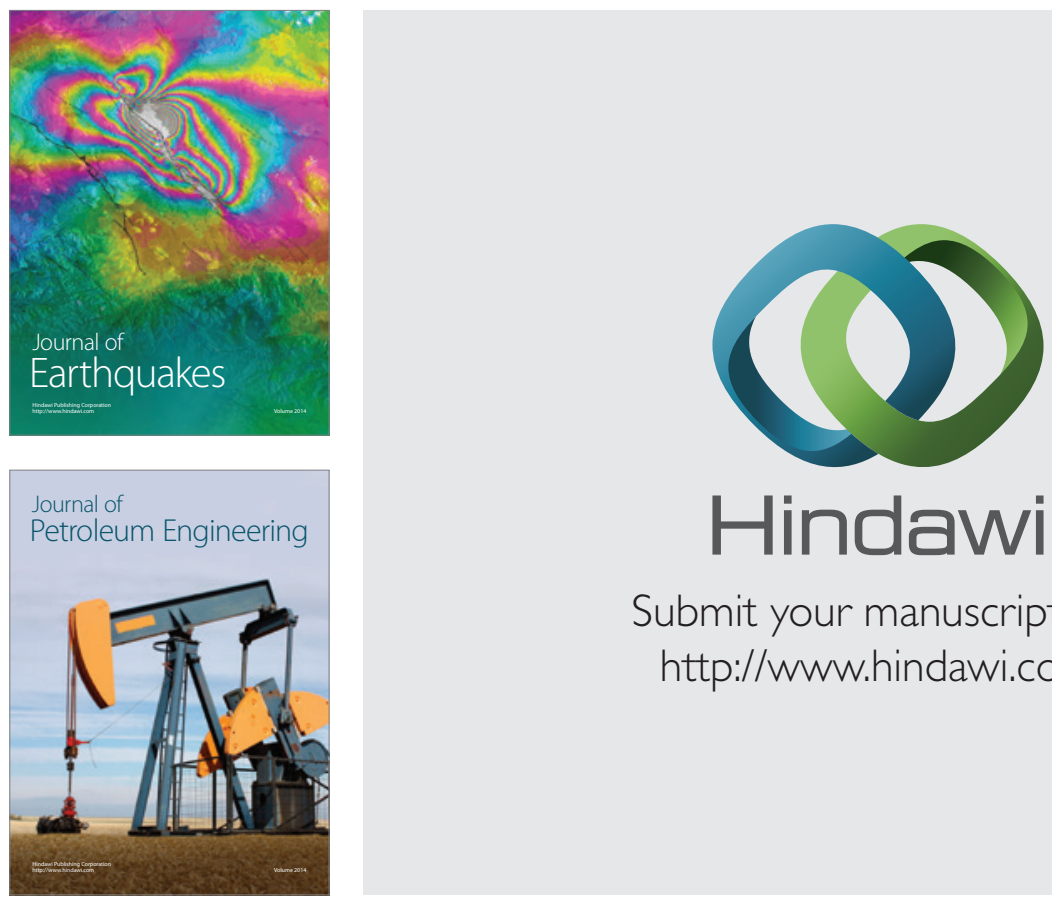

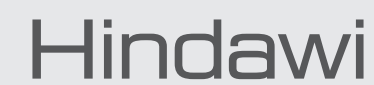

Submit your manuscripts at

http://www.hindawi.com
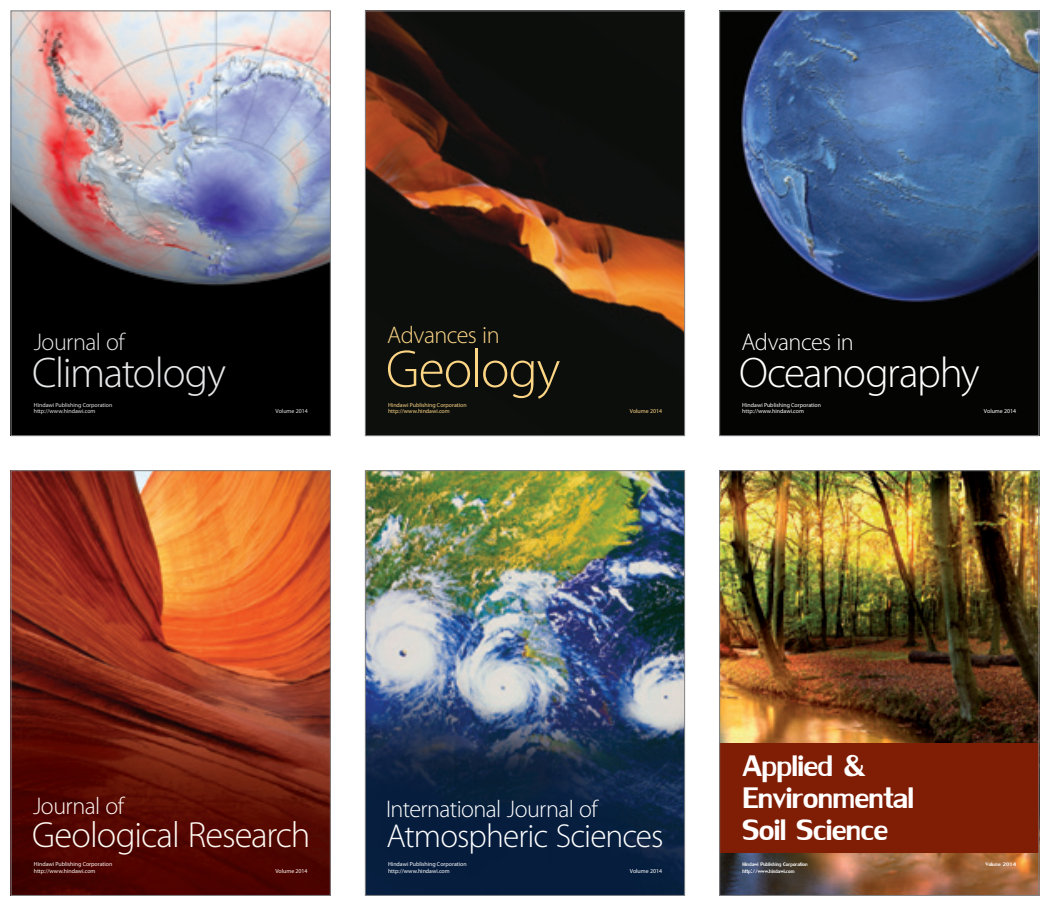
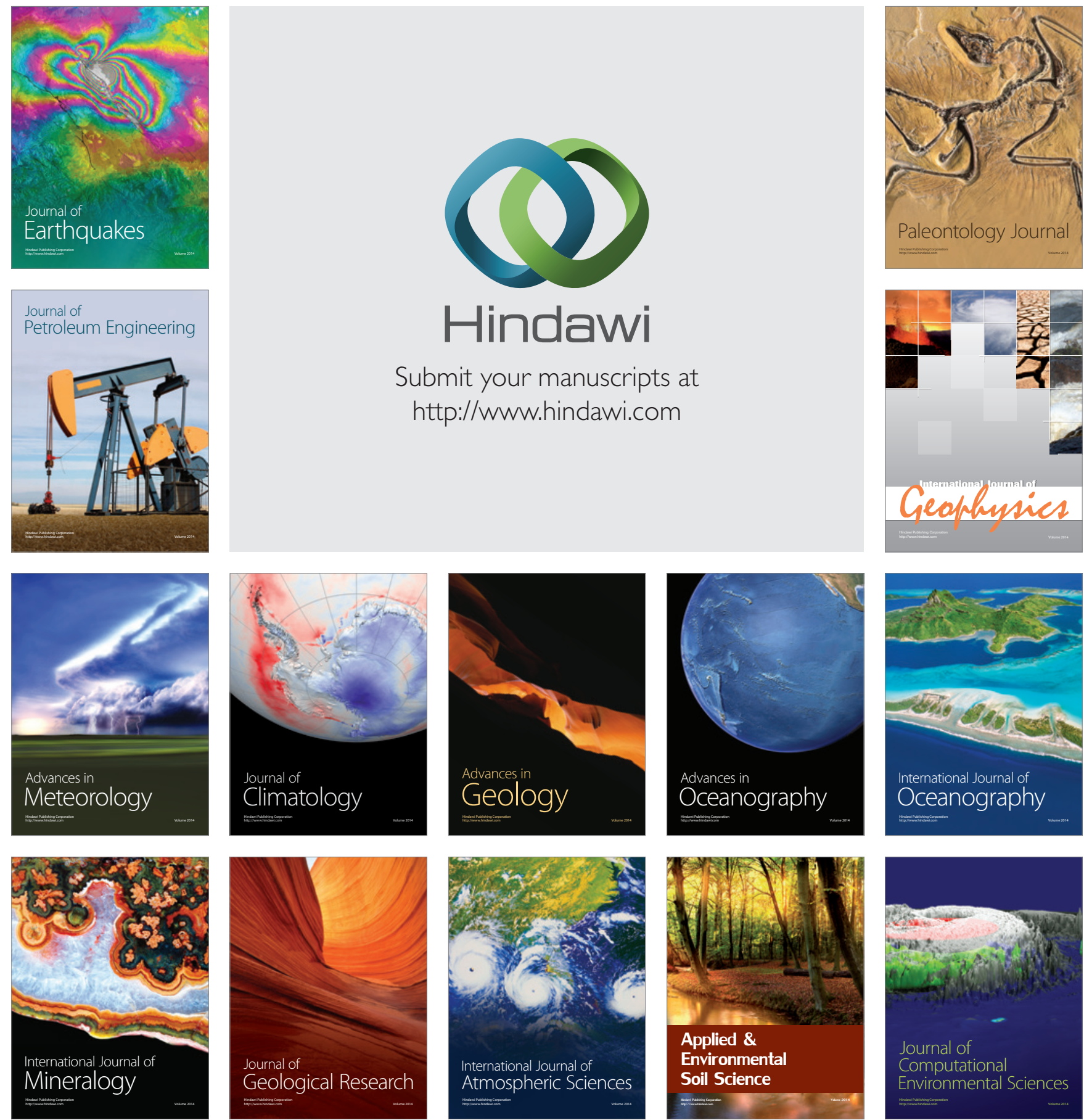